\section{SOI: $1.1 /$ TAS $\quad$ DOI: $10.15863 /$ TAS \\ International Scientific Journal Theoretical \& Applied Science}

\author{
p-ISSN: 2308-4944 (print) e-ISSN: 2409-0085 (online) \\ Year: 2018 Issue: 02 Volume: 58 \\ Published: 28.02.2018 http://T-Science.org
}

\author{
S.A. Iskhakova \\ Senior Lecturer \\ Samarkand branch of the Tashkent University \\ of Information Technologies, \\ Uzbekistan, Samarkand
}

SECTION 31. Economic research, finance, innovation, risk management.

\title{
ANALYSIS OF THE EFFECTIVENESS OF THE MECHANISM OF FORMATION OF INCOMES OF WORKERS OF SPHERE OF EDUCATIONAL SERVICES
}

\begin{abstract}
The educational system of Uzbekistan has been transformed in recent years. The system of financing of educational institutions is constantly changing, which directly affected the income of teachers. It is important to understand that the system of remuneration depends on the characteristics of educational services, but there's no doubt that the Foundation of financial security should be social efficiency and effectiveness expressed in quality of the provided knowledge.

The article notes that Uzbekistan is actively developing, as evidenced by the GDP growth scenario forecasts 2017-2018 Educational system must comply with industry recovery and to establish effective mechanism for ensuring human capital. The faculty income have a direct impact on the efficiency of the educational system as a whole.

Key words: education, budget allocations, per capita funding, income, wages.

Language: Russian

Citation: Iskhakova SA (2018) ANALYSIS OF THE EFFECTIVENESS OF THE MECHANISM OF FORMATION OF INCOMES OF WORKERS OF SPHERE OF EDUCATIONAL SERVICES. ISJ Theoretical \& Applied Science, 02 (58): 199-204.

Soi: http://s-o-i.org/1.1/TAS-02-58-40 Doi: crossef https://dx.doi.org/10.15863/TAS.2018.02.58.40 \section{СФЕРЫ ОБРАЗОВАТЕЛЬНЫХ УСЛУГ}

АНАЛИЗ ЭФФЕКТИВНОСТИ МЕХАНИЗМА ФОРМИРОВАНИЯ ДОХОДОВ РАБОТНИКОВ

Аннотация: Образовательная система Узбекистана значительно трансформировалась в последние годы. Система финансирования образовательных учреждений также претерпела изменений, что непосредственным образом отражалось на доходах преподавательских кадров. Важно понимать, что система оплаты труда напрямую зависит от особенностей предоставляемых образовательных услуг и основой финансового обеспечения должна являться сочиальная эффективность и результативность, выраженная в качестве предоставленных знаний.

В статье отмечается, что Узбекистан активно развивается, о чем свидетельствует рост ВВП. Образовательная система должна соответствовать экономическому подъему и формировать эффективный механизм развития человеческого капитала. Доход преподавательского состава непосредственным образом влияет на эффективность образовательной системь в целом.
\end{abstract}

Ключевые слова: образование, бюджетные ассигнования, финансирования, доход, оплата труда.

\section{Introduction}

В современных условиях образовательная политика Республики Узбекистан направлена на максимальную интеграцию в мировое сообщество Президент Ш.М.Мирзиёев акцентируя внимание на том «..., что это в первую очередь связано с совершенствованием системы образования и просвещения, приобщением нашей молодежи - будущего страны - к самым современным знаниям, воспитанием всесторонне и гармонично развитой личности» [1.c.1].

В целях кардинального совершенствования системы высшего образования, коренного пересмотра содержания подготовки кадров в соответствии с приоритетными задачами социально-экономического развития страны, обеспечения необходимых условий для подготовки специалистов с высшим образованием на уровне международных 
стандартов необходимо «..дальнейшее совершенствование образовательного процесса, учебных планов и программ высшего образования на основе широкого использования новейших педагогических технологий и методов обучения, качественное обновление и внедрение современных форм организации научнообразовательного процесса... » [6.c.1].

\section{Materials and Methods}

Формирование новых подходов в образовании обусловлены также реформами экономики и ростом промышленности в Узбекистане. Недостаток квалифицированных кадров, по данным Всемирного банка, существует во всех отраслях экономики Узбекистана.

Необходимо отметить, что в рамках реализации Программы модернизации материально-технической базы высших образовательных учреждений и кардинального улучшения качества подготовки специалистов на 2011-2016 годы осуществлены работы по новому строительству, реконструкции и капитальному ремонту на 202 объектах в 25 высших образовательных учреждениях. Исходя из потребностей реального сектора экономики, увеличен прием на обучение по инженерным, производственным и строительным направлениям и специальностям с 23 процентов до 33,2 процента от общего количества. Внедрены обновленные государственные образовательные стандарты и учебные программы подготовки специалистов высшего образования, а также переподготовки и повышения квалификации педагогических кадров.

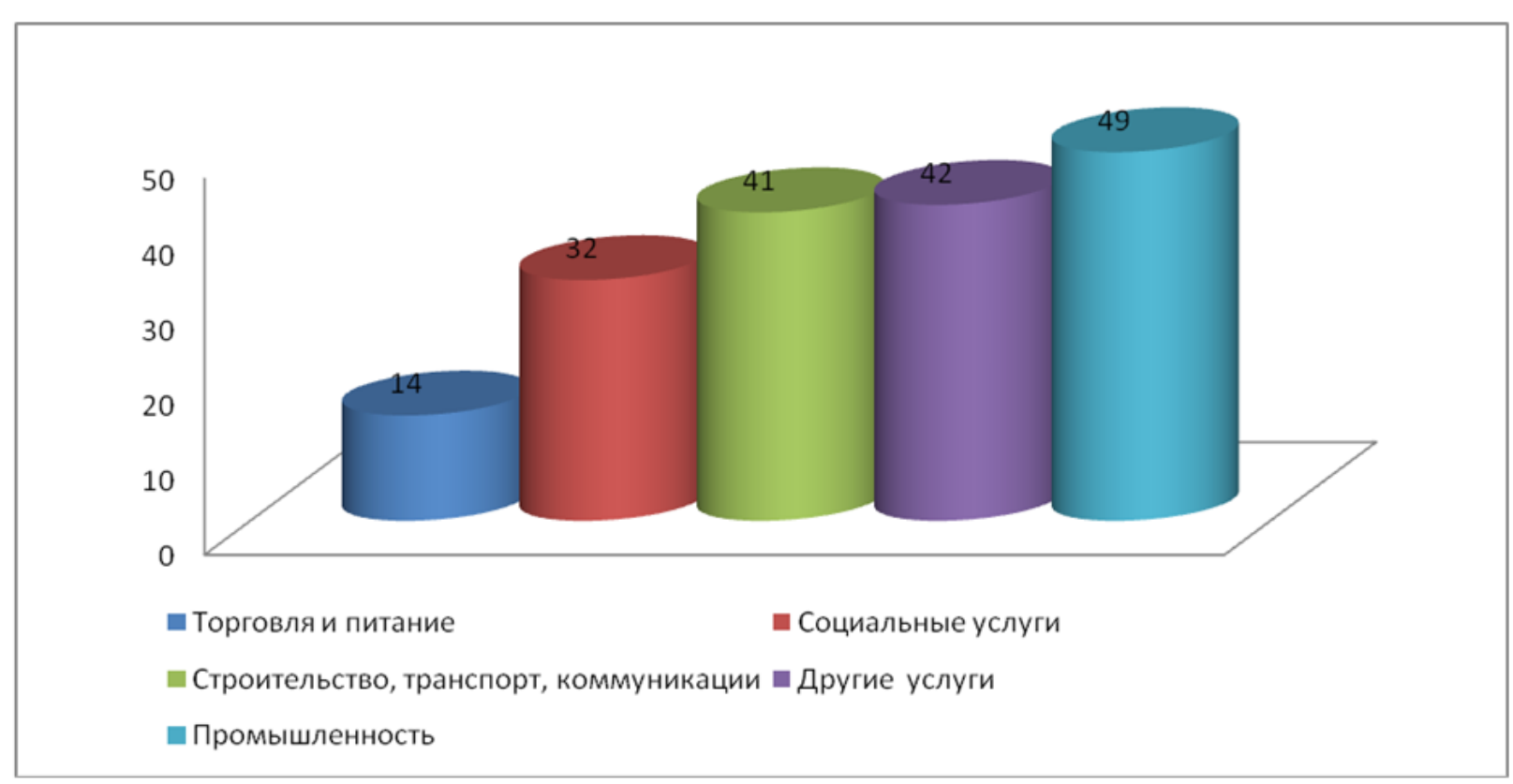

Рисунок 1. Доля компаний, испытывающих трудности с подбором квалифицированного персонала[2]

Обеспечение образовательной системы Республики Узбекистан высококвалифицированными кадрами напрямую зависит от финансового обеспечения в целом, и стимулирования труда работников этой сферы, в частности. От того, насколько стимулируется труд в данной сфере, как оплачивается труд работников, насколько эффективна система государственной поддержки и способствует ли сложившийся механизм формирования доходов достижению высокой эффективности во многом зависит качество подготавливаемых кадров.

Следует отметить, что на волне экономического подъема (рост ВВП Узбекистана в 2017 году превысил 5,3\%) [3] изменились и доходы населения. Заработная плата бюджетников в 2017 г. выросла на 15,0\%, доходы населения увеличились на $11,0 \%$. Минимальная оплата труда с 1 декабря 2017 года составила 172240,0 сумов (21,1 долл. США), минимальная пенсия по возрасту - 336880,0 сумов (41,3 долл. США) [9].

В процессе исследования нами был произведен анализ механизма формирования доходов работников высших учебных заведений и установлено, что в вузах республики Узбекистан на протяжении многих лет функционировала Единая тарифная система оплаты труда работников, которая имела ряд недостатков, снижающих стимулирующий эффект единой тарифной системы. 
Для устранения этих недостатков в вузах республики Узбекистан на основе Постановления Кабинета Министров республики от 24 июля 2008 года № ПКМ-926 «О мерах по совершенствованию системы оплаты и усилению материального стимулирования труда работников высших образовательных учреждений республики»[4] и Положения «Об оплате труда работников высших учебных заведений» вместо традиционной тарифной системы (ЕТС), с гарантированными тарифными ставками и должностными окладами, повременной и сдельной оплатой труда с 1 сентября 2008 года был осуществлен переход к новой усовершенствованной системе оплаты труда работников этой сферы. Согласно этим нормативным документам в вузах республики были введены базовые должностные оклады по оплате труда профессорско-преподавательского состава и руководящих работников высших образовательных учреждений. На основе этих документов заработная плата работников высших учебных заведений формируется из:

$\square$ базовых окладов, назначаемых для каждой должности профессорскопреподавательского состава и руководящих работников вузов;

$\square$ надбавок и доплат, предусмотренных законом.

Базовые должностные оклады профессорскопреподавательского состава дифференцируются в зависимости от штатной должности и наличия ученой степени, ученого звания.

В последующем во исполнение указов Президента Республики Узбекистан от 7 февраля 2017 года №УП-4947 «О Стратегии действий по дальнейшему развитию Республики Узбекистан» и от 16 февраля 2017 года № УП-4958«О дальнейшем совершенствовании системы послевузовского образования» [5], постановления Президента Республики Узбекистан от 20 апреля 2017 года № ПП-2909 «О мерах по дальнейшему развитию системы высшего образования», а также в целях дальнейшего повышения качества высшего образования, создания условий для подготовки высококвалифицированных специалистов Кабинетом Министров были внесены изменения и дополнения в постановление Кабинета Министров Республики Узбекистан от 24 июля 2008 года № ПКМ-926 «О мерах по совершенствованию системы оплаты и усиления материального стимулирования труда работников высших учебных заведений» [7] и Положения «Об оплате труда работников высших учебных заведений» на основе Постановления Кабинета Министров от 11 августа 2011года №ПКМ-617 “О внесении изменений и дополнения в Постановление Кабинета Министров республики
Узбекистан от 1 августа 2008 г. № 164 «Об утверждении усовершенствованной системы оплаты труда работников высших образовательных учреждений республики» [8]были внесены изменения и дополнения.

$$
\text { Согласно этому Постановлению }
$$
ииндивидуальный план работы профессорскопреподавательского состава включает в себя перечень основных мероприятий учебного, учебно-методического, научноисследовательского, организационного и духовно-просветительского характера. Трудовая деятельность профессорско-преподавательского состава по учебно-методическим, научноисследовательским, организационным, духовнопросветительским работам осуществляется без исчисления объема часов, на основе видов и содержания работ, в соответствии с предъяляемыми квалификационными требованиями к должностям. Кроме этого введены в действие с 1 сентября 2017 года разряды оплаты труда управленческого, технического, обслуживающего и учебно-вспомогательного персонала высших образовательных учреждений.

Материальное стимулирование профессорско-преподавательского состава и других категорий работников высших учебных заведений осуществляется в виде денежных вознаграждений-премий, а также устанавливаемых руководством надбавок и доплат к их основной заработной плате за высокие творческие и производственные достижения в работе за счет и в пределах образованного в установленном порядке внебюджетного Фонда. Размеры надбавок, доплат и премий дифференцировано устанавливаются в зависимости от личного вклада каждого работника в повышение качества проводимых мероприятий, выполняемых работ (услуг), рост доходов учебных заведений.

Премии, доплаты и надбавки к заработной плате выплачиваются из Фонда материального стимулирования учебных заведений, образованного в установленном порядке из внебюджетных средств, в размерах, установленных постановлением Кабинета Министров Республики Узбекистан от 5 июля 1996 года № 236 для профессорскопреподавательского состава, а для других категорий работников учебных заведений по решению ректоратов и согласованию с профсоюзной организацией. Источником образования фонда материального поощрения учебного заведения являются внебюджетные средства, поступающие за подготовку кадров на платно-контрактной основе, от выполнения проектно-изыскательских, конструкторских, технологических разработок спонсорства, коммерческой деятельности и от других видов 
образовательных услуг. Из общего объема средств, поступающих за подготовку специалистов на платно-контрактной основе и других видов образовательных услуг, не более 30 процентов могут направляться на материальное стимулирование профессорскопреподавательского состава и других категорий работников высших учебных заведений.

Установление базовых должностных окладов является шагом вперед по сравнению с ЕТС, но и эта система оплаты труда, по нашему мнению, имеет некоторые недостатки. В частности, при установлении базовых окладов не учитывается стаж работы профессорско-преподавательского состава.

Нами был произведен сравнительный анализ систем оплаты труда работников образовательных учреждений Российской Федерации и Республики Узбекистан. Данный анализ систем по определенным критериям представлен в таблице 3.

Представленный анализ свидетельствует о том, что обе системы оплаты труда направлены на улучшение качества работы педагогов. Но необходимо отметить, что они имеют некоторые отличия (таблица 3). Как видно из таблицы, заработная плата преподавателей в России формируется из должностного оклада, который рассчитывается исходя из базового оклада (в зависимости от должности), к которому применяются повышающие коэффициенты (за повышение квалификации, за выслугу лет). В Узбекистане заработная плата преподавателя состоит из базового оклада, который устанавливается исходя из занимаемой должности, но к нему коэффициент не применяется.

Таблица 3.

\section{Сравнительный анализ системы оплаты труда работников сферы образования} Российской Федерации и Узбекистана

\begin{tabular}{|c|c|c|}
\hline \multirow{2}{*}{ Критерии } & \multicolumn{2}{|c|}{ Система оплаты труда } \\
\hline & Российской Федерации & Республика Узбекистан \\
\hline $\begin{array}{c}\text { Применяемая модель для } \\
\text { формирования оплаты труда }\end{array}$ & $\begin{array}{c}\text { Базовый оклад + } \\
\text { повышающий коэффициент }\end{array}$ & Базовый оклад \\
\hline $\begin{array}{c}\text { Формула формирования } \\
\text { заработной платы }\end{array}$ & $\begin{array}{c}\text { ЗП = Базовый оклад + повышающий } \\
\text { коэффициент + компенсационные } \\
\text { выплаты + стимулирующие выплаты. }\end{array}$ & $\begin{array}{c}\text { ЗП = Базовый оклад + } \\
\text { надбавки и доплаты }\end{array}$ \\
\hline $\begin{array}{c}\text { Гарантированный уровень } \\
\text { оплаты труда }\end{array}$ & $\begin{array}{c}\text { Базовый оклад } \\
\text { (установленный учреждением) + } \\
\text { повышающий коэффициенты }\end{array}$ & $\begin{array}{c}\text { Базовый оклад } \\
\text { (установленный учреждением) } \\
\text { +надбавки и доплаты }\end{array}$ \\
\hline Стимулирующий фонд & $\begin{array}{c}\mathrm{CT}=\text { ФОТ - гарантируемый уровень } \\
\text { оплаты труда }\end{array}$ & $\begin{array}{c}\mathrm{CT}=\text { ФОТ - гарантируемый уровень } \\
\text { оплаты труда }\end{array}$ \\
\hline Фонд оплаты труда & В соответствии с финансированием & $\begin{array}{c}\text { В соответствии с финансированием } \\
\text { по штатному расписанию и } \\
\text { тарификацию }\end{array}$ \\
\hline $\begin{array}{c}\text { Нормативно - правовое } \\
\text { обеспечение }\end{array}$ & $\begin{array}{l}\text { Положение об оплате труда } \\
\text { работников образ. учреждения; } \\
\text { трудовое соглашение с работником }\end{array}$ & $\begin{array}{l}\text { Коллективный договор; Положение } \\
\text { об оплате труда работников высших } \\
\text { учебных заведений; Положение о } \\
\text { порядке материального } \\
\text { стимулирования профессорско- } \\
\text { преподавательского состава. } \\
\text { Внебюджетных }\end{array}$ \\
\hline
\end{tabular}




\begin{tabular}{|c|c|c|}
\hline \multirow{2}{*}{$\begin{array}{c}\text { Участие } \\
\text { общественности в } \\
\text { распределении стимул. Выплат }\end{array}$} & $\begin{array}{c}\text { Согласование со специальной } \\
\text { Согование с проф. организацией, } \\
\text { согласование с общественностью } \\
\text { комиссиеи в составе ректор - } \\
\text { предатель комиссии; проректора, } \\
\text { не менее двух представителей } \\
\text { педагогического коллектива, } \\
\text { председателя профсоюзной } \\
\text { организации; }\end{array}$ \\
\hline
\end{tabular}

\section{Conclusion}

В России к должностному окладу прибавляется сумма компенсационных выплат и доплат, которые устанавливаются за дополнительные работы, например, руководство группой и др., а также сумма стимулирующих выплат (учебные достижения студентов, призовые места на олимпиадах и т.д.). Данные выплаты устанавливаются образовательным учреждением самостоятельно на основе разработанных положений данного учреждения. Компенсационные выплаты предполагают материальное вознаграждение за виды работ, сопровождающие учебный процесс. Доля стимулирующих и компенсационных выплат в оплате труда педагогов составляют не более $50 \%$ от величины должностных окладов.

В Узбекистане к базовому окладу прибавляются доплаты и надбавки, которые устанавливаются в зависимости от результатов учебной деятельности обучающихся, их успехов в образовании, результатов итоговой аттестации, качества подготовки, которое подтверждается победами на различных конкурсах. Важное значение также имеют успехи самих педагогов это победы на конкурсах профессионального мастерства, регулярное повышение квалификации, дополнительные виды деятельности, связанные с работой с одаренными студентами и так далее.

Таким образом, образовательное учреждение непосредственно заинтересовано в формировании адекватной системы оплаты труда, которая позволяет привлекать высококвалифицированный педагогический состав, повышать успехи обучающихся и, в результате, повышать конкурентоспособность самого образовательного учреждения.

Совершенствование системы оплаты труда работников сферы образования требует разработки четких критериев эффективности труда педагогов. В свое время такие критерии были разработаны, но к сожалению данный подход не принес ощутимых результатов. Дело в том, что снижение оплаты труда по критерию «уровень успеваемости» привел к необходимости завышать оценки ученикам. Критерий «научная деятельность» значительно повысил занятость педагогов.

В качестве критериев следует наряду с успешностью учебной деятельности ввести оценку коммуникативных навыков (работа с родителями), инновационная активность (задействованность ИКТ в учебном процессе), уровень достижений обучающихся во внеучебной деятельности по предмету (например, участие в олимпиадах по предмету).

Для усиления стимулирующей функции заработной платы необходимо повышения ее гибкости, объективности оценки достижений работников. Обеспечение гибкости применяемых систем оплаты труда позволит адекватно реагировать на изменение результатов труда работника через индивидуальное определение заработка каждого работника, на основе учета его заслуг. Оценка заслуг означает, что работники, имеющие одинаковую квалификацию и занимающие одну должность, благодаря своим природным способностям, стажу, целевым установкам, мотивам и стремлениям, могут добиться различных результатов в работе. Эти различия должны найти отражение в заработной плате, что достигается дифференциацией окладов в рамках должностных окладов. В действующей в настоящее время системе оплаты труда разница в оплате между должностными окладами очень незначительная.

Считаем также, целесообразным дифференцировать размер минимальной заработной платы в зависимости от продуктивности отрасли и постепенно приблизить её к прожиточному минимуму. Рекомендуется определять бюджет стимулирующих доплат 30-35\% от ФОТ.

Bce вопросы организации оплаты труда работников вузов должны решать сами коллективы с учетом их особенностей, качественного состава персонала, финансовых возможностей. На этой основе будет происходить постепенное сближение размеров оплаты труда 
работников бюджетного сектора с рыночным сектором.

В связи с этим для усиления стимулирующей роли заработной платы и учета творческого элемента труда работников сферы образования, необходимо разработать систему мотивации труда, направленную на детальный учет достигнутых результатов каждым работником. При этом для количественной оценки вклада творческого труда работника предлагается определение коэффициента учета заслуг каждого работника. Для этого нужно разработать шкалу коэффициента учета заслуг работника в зависимости от занимаемой должности. Дальше базовый оклад оплаты труда, соответствующий выполняемой им работе корректируется с учетом коэффициента учета заслуг работника, учитывающий качество, напряженность и творческий характер труда, что является очень важным для образовательных учреждений.

Таким образом, предлагаемая система оплаты труда направлена на увязку размера зарплаты с реальным вкладом каждого работника в результаты деятельности предприятия. Действовавший ранее принцип оплаты по труду трансформируется в принцип оплаты по результатам деятельности предприятия.

Помимо всего этого само образовательное учреждение должно заботиться о достойном стимулировании оплаты труда своих сотрудников. Для этих целей необходимо вводить дополнительные платные услуги, за счет которых и будут производиться поощрительные и стимулирующие выплаты для сотрудников, которые были непосредственно задействованы в оказании разного рода платных услуг. Возможностью для изыскания дополнительных средств можно использовать поиск спонсоров и меценатов, за счет которых будет возможно повышение оплаты труда.

Предложенные мероприятия должны повысить эффективность системы оплаты труда в образовательных учреждениях.

\section{References:}

1. Mirzieev Sh.M. (2016) «Prosveshchenie i obrazovanie yavlyayutsya klyuchom k protsvetaniyu narodov»». Doklad na 43-ey sessii Soveta ministrov inostrannykh del Organizatsii islamskogo sotrudnichestva. 18 oktyabrya 2016.

2. (2017) Vysshee obrazovanie v Uzbekistane i trebovaniya 21-go veka. Available: http://www.vsemirnyjbank.org/ru/news/feature/ 2014/09/02/tertiary-education-in-uzbekistanmeeting-21st-century-challenges/ (Accessed: 22.09.2017).

3. (2017) Vsemirnyy bank: VVP Uzbekistana vyrastet na $7,4 \%$ v etom godu. Available: http://kommersant.uz/news/world-bankuzbekistan/ (Accessed: 22.09.2017).

4. (2008) Postanovleniya Kabineta Ministrov respubliki Uzbekistan ot 24 iyulya 2008 goda № PKM-926 «O merakh po sovershenstvovaniyu sistemy oplaty i usileniyu material'nogo stimulirovaniya truda rabotnikov vysshikh obrazovatel'nykh uchrezhdeniy respubliki». Available: https://www.lex.uz (Accessed: 10.02.2018).

5. (2017) Ukazy Prezidenta Respubliki Uzbekistan ot 7 fevralya 2017 goda №UP-4947 «O Strategii deystviy po dal'neyshemu razvitiyu Respubliki Uzbekistan» i ot 16 fevralya 2017 goda № UP$4958 \ll \mathrm{O}$ dal'neyshem sovershenstvovanii sistemy poslevuzovskogo obrazovaniya». Available: https://www.lex.uz (Accessed: 10.02.2018).

6. (2017) Postanovlenie Prezidenta Respubliki Uzbekistan ot 20 aprelya 2017 goda № PP-2909 «O merakh po dal'neyshemu razvitiyu sistemy vysshego obrazovaniya». Available: https://www.lex.uz (Accessed: 10.02.2018).

7. (2008) Postanovlenie Kabineta Ministrov Respubliki Uzbekistan ot 24 iyulya 2008 goda № PKM-926 «O merakh po sovershenstvovaniyu sistemy oplaty i usileniya material'nogo stimulirovaniya truda rabotnikov vysshikh uchebnykh zavedeniy». Available: https://www.lex.uz (Accessed: 10.02.2018).

8. (2008) Postanovlenie Kabineta Ministrov ot 11 avgusta 2011goda №PKM-617 “O vnesenii izmeneniy i dopolneniya $\mathrm{v}$ Postanovlenie Kabineta Ministrov respubliki Uzbekistan ot 1 avgusta 2008 g. № 164 «Ob utverzhdenii usovershenstvovannoy sistemy oplaty truda rabotnikov vysshikh obrazovatel'nykh uchrezhdeniy respubliki». Available: https://www.lex.uz (Accessed: 10.02.2018).

9. (2017) Ukaz Prezidenta ot 20.11.2017 g. № UP$5245 \ll O$ povyshenii razmera zarabotnoy platy, pensiy, stipendiy i posobiy». Available: https://www.norma.uz (Accessed: 10.02.2018). 